\title{
Anabases
}

ANABASES Traditions et réceptions de l'Antiquité

4 | 2006

Varia

\section{Anthologie de la littérature latine, Préface de J. Gaillard, Choix présenté et traduit par J. GAILLARD \& \\ R. MARTIN}

Olivier Devillers

\section{OpenEdition}

\section{Journals}

Édition électronique

URL : http://journals.openedition.org/anabases/2860

DOI : 10.4000/anabases. 2860

ISSN : 2256-9421

\section{Éditeur}

E.R.A.S.M.E.

\section{Édition imprimée}

Date de publication : 1 octobre 2006

Pagination : 307-309

ISSN : 1774-4296

\section{Référence électronique}

Olivier Devillers, «Anthologie de la littérature latine, Préface de J. Gaillard, Choix présenté et traduit par J. Gaillard \& R. Martin », Anabases [En ligne], 4 | 2006, mis en ligne le 01 mai 2012, consulté le 22 septembre 2020. URL : http://journals.openedition.org/anabases/2860 ; DOI : https://doi.org/ $10.4000 /$ anabases. 2860

Ce document a été généré automatiquement le 22 septembre 2020

(c) Anabases 


\title{
Anthologie de la littérature latine, Préface de J. Gaillard, Choix présenté et traduit par J. GAILLARD \& R. MARTIN
}

\author{
Olivier Devillers
}

\section{RÉFÉRENCE}

Anthologie de la littérature latine, Préface de J. Gaillard, Choix présenté et traduit par J. GAILLARD \& R. MARTIN, (collection Folio Classique, 4272), Paris, Gallimard, 2005, 576 p. 6,20 euros / ISBN 2-07-042628-9.

1 Poursuivant leurs travaux communs sur la littérature, J. Gaillard et R. Martin livrent une anthologie de la littérature latine « païenne » rassemblant, en un peu plus de 500 pages, des extraits traduits (d'après le texte fourni par les éditions de la CUF) de 29 auteurs (dont un poème d'une " auteure ", Sulpicia) de Plaute à Apulée. L'objectif est d'inciter à la lecture et même, plus précisément, au plaisir de la lecture. Pour y parvenir, J. Gaillard et R. Martin (on trouve p. 37, n. 1, la liste des auteurs latins dont chacun s'est chargé) ont systématiquement privilégié les choix qui permettent de serrer au plus près la personnalité des écrivains. D'une part, pour ce qui est de la sélection, ils ne multiplient pas les textes courts (même s'il y en a) et ne craignent pas de reproduire des extraits assez longs où l'on voit se déployer le style et la pensée des auteurs; de même, ils ne se focalisent pas sur les «belles pages » (même s'il y en a, à nouveau), mais cherchent à mettre en valeur des passages représentatifs. D'autre part, pour ce qui est des traductions, qui sont originales, ils dépassent le style standardisé des traductions "correctes" et tendent à rendre le ton et le niveau de langue des originaux - leur «musique particulière » en quelque sorte - ; ce souci se marque de la façon la plus spectaculaire pour les poètes qui sont traduits en vers. Par leur constance 
dans l'application de ces options de départ, leur livre, qui vise à s'insérer «dans le champ ordinaire de la consommation littéraire» (p.34), apparaît comme une incontestable réussite et pour ce qui me concerne, ce fut effectivement un "plaisir ", après avoir dévoré les 40 pages initiales consacrées à Plaute, de naviguer dans cette anthologie, allant d'une île à l'autre, au hasard des découvertes et des redécouvertes. C'est assurément un tour de force que d'être parvenu, en étant deux traducteurs seulement, à « rendre " (et donc à avoir " capté ») l'esprit de textes si divers émanant de près de trente auteurs. Ainsi, tant par sa conception que par sa réalisation, ce livre semble en mesure de toucher un public plus vaste que celui des latinistes acquis par avance et, sinon de lui donner le goût de la littérature latine, du moins de transformer en intérêt ce qui n'était peut-être au départ que curiosité de sa part. Nous soulignerons aussi ce qu'apporte à la compréhension de l'anthologie la préface signée par J. Gaillard (p. 7-49), lequel, de sa plume vive et riche en formules, aborde avec franchise deux grandes problématiques, celle du paradoxe de la «survie» des textes de l'Antiquité (une réflexion qui vaut aussi pour le domaine grec) et celle de leur traduction. Nous mentionnerons enfin les notices introductives qui présentent chaque texte, chaque œuvre, chaque auteur, bien que, pour ces derniers, la mention systématique d'écrivains «modernes ", soit à titre de comparaison, soit pour illustrer la survie (entre autres, Pagnol et Labiche pour Plaute, Diderot pour Térence, Napoléon pour César, Claudel pour Virgile, Apollinaire et Gainsbourg pour Horace, Rousseau pour Sénèque, Shakespeare pour Stace, Hugo pour Tacite...), paraisse à la longue plus rituelle que réellement incitative. Quelques autres "petits» regrets. D'abord, mais ceci est inévitable pour toute entreprise de ce genre, on relèvera quelques absences, notamment celle de Cornelius Nepos, et spécialement de la Vie d'Atticus, dont je ne suis pas d'avis qu'elle relève d'une "absolue platitude " (p. 37), ou de Velleius Paterculus, pratiquement le seul auteur conservé pour l'époque de Tibère, dont la description de la défaite de Varus n'est pas dénuée de souffle; pour ce qui est des auteurs retenus, aucun des textes choisis pour les Annales de Tacite ne concerne Tibère, dont le principat est souvent dépeint de manière saisissante et selon des modes qui diffèrent de ceux par lesquels est décrit le "monstre " Néron; pour Sénèque, les Lettres à Lucilius occupent une grande place, alors que les Naturales Quaestiones, absentes ici, ne manquent pas de passages qui illustrent la morale et la conception du monde du philosophe; un seul extrait des Géorgiques laisse sur sa faim (encore, s'il eût été du livre IV !) ; rien pour la quatrième décade de Tite-Live... Ensuite, de temps en temps, une note explicative supplémentaire en bas de page n'aurait pas été inutile, par exemple, à la p. 464, sur la chute de Vitellius, pour signaler que Flavius Sabinus est le frère de Vespasien... Enfin, les coupures dans les textes ne sont pas toujours heureuses, en particulier aux pages 165-166, où le texte est interrompu au milieu d'un exposé de Pompée et reprend au cours d'une description de la situation selon le point de vue de César. 


\section{AUTEURS}

\section{OLIVIER DEVILLERS}

Université Bordeaux III - Michel de Montaigne

oldevillers@wanadoo.fr 